\title{
An Approximate Analytical Solution Of Nonlinear Equations In N-Aminopiperidine Synthesis: New Approach Of Homotopy Perturbation Method)
}

\author{
${ }^{1}$ R. Joy Salomi, ${ }^{2}$ S. Vinolyn Sylvia, ${ }^{3}$ L. Rajendran \\ ${ }^{1}$ Department of Mathematics, \\ Academy of Maritime Education and Training (AMET) Deemed to be University, \\ Chennai, India. \\ prjoysalomi@gmail.com \\ ${ }^{2}$ Department of Mathematics, \\ Academy of Maritime Education and Training (AMET), Deemed to be University, \\ Chennai, India. \\ svs9196@gmail.com \\ ${ }^{3}$ Department of Mathematics \\ Academy of Maritime Education and Training (AMET), Deemed to be University, \\ Chennai, India. \\ Corresponding author: \\ raj_sms@rediffmail.com
}

Article History: Received: 11 January 2021; Accepted: 27 February 2021; Published online: 5 April 2021

\begin{abstract}
N-aminopiperidine (NAPP) using hydroxylamine-O-sulfonic acid (HOSA) is based on system of nonlinear rate equations. The new approach to homotopy perturbation method is applied to solve the nonlinear equations. A simple analytical expression for concentrations of hydroxylamine-O-sulfonique acid (HOSA), piperidine (PP), N-aminopiperidine (NAPP), sodium hydroxide $(\mathrm{NaOH})$ and diazene $\left(\mathrm{N}_{2} \mathrm{H}_{2}\right)$ along with NAPP yield is obtained and is compared with numerical result. Satisfactory agreement is obtained in the comparison of approximate analytical solution and numerical simulation. The obtained analytical result of NAPP yield is compared with the experimental results. The influence of reagents ratio $\mathrm{p}$ and rate constants ratio $\mathrm{r}$ on yield has been discussed.
\end{abstract}

Keywords-Kinetic modelling; Nonlinear rate equations; Mathematical modelling; Synthesis of NAPP; Homotopy perturbation method

\section{INTRODUCTION}

Several problems in biology and chemistry (both theoretical and experimental) involve the solution of reaction equations, including nonlinear chemical kinetics. Most of them do not have a precise analytical solution, so these nonlinear equations should be solved using approximate methods. For a great overview of nonlinear differential equations, see the books by L. Rajendran, R. Swaminathan and M. Chitra Devi [1] and L. Rajendran, M. Chitra Devi, C. Fernandez and Q. Peng with a particular focus on mathematical resolution.

Residual method [3], variational iteration method [4], Adomian decomposition method [5], homotopy perturbation method (HPM) [6] are some of the techniques that can be used to solve nonlinear differential equations. Combining the traditional perturbation method and the homotopy in topology given rise to the homotopy perturbation method. It provides an approximate analytical solution to a variety of nonlinear problems in applied sciences [7,8]. This HPM has also been successfully used to solve Laplace equations, heat radiation equations, nonlinear integral equations, nonlinear heat conduction and convection equations, nonlinear oscillators, nonlinear wave equations and nonlinear rate equations [9].

He and El- Dib [10] solved the singular Duffing-like oscillator problem more effectively using homotopy perturbation method. For the nonlinear problems in nano/microelectromechanical systems, Naveed and He [11] applied the homotopy perturbation and He-Laplace technique. Yue Wu and He [12] showed that the homotopy perturbation method could be effectively applied to nonlinear oscillators with no linear term or negative linear term by the parameter expansion method.

Abbasbandy [13] applied HPM to obtain the Laplace transform. He's homotopy-perturbation method was introduced to overcome the difficulties arising in calculating Adomian polynomials [14]. M. Rafei, D.D. Ganji and H. Daniali [15] used the HPM to determine an approximation of the epidemic model's solution. Yildirim and Ozis also applied the homotopy perturbation method to solve the problem of singular IVPs of the LaneEmden-type [16]. Yildirim [17] also derived the exact solutions of nonlinear differential-difference equations using the homotopy perturbation method. R. Singh, S. Singh and A.M. Wazwaz [18] solved nonlinear and singular time-dependent Emden-Fowler type equations with the Neumann and Dirichlet boundary conditions using a new modification of the homotopy perturbation method. 
R. Swaminathan, K. Lakshmi Narayanan, V. Mohan, K. Saranya and L. Rajendran [19] reported the usage of new approaches to solving nonlinear partial differential equations in microdisk biosensors using the homotopy perturbation method (HPM) for the first time. K. Saranya, V. Mohan, R. Kizek, C. Fernandez and L. Rajendran [20] discussed the theoretical model of glucose oxidation and hydrogen peroxide production in the chitosanalginate microsphere and also obtained approximate analytical expression for the concentration of glucose, oxygen, gluconic acid and hydrogen peroxide using HPM. K. Saranya, V. Mohan, R. Kizek, C. Fernandez and L. Rajendran [21] solved the mathematical problem corresponding to a one-electron reversible electron transfer at a rotating disk electrode by using HPM under transient and steady-state conditions.

E. Labarthe, A.J. Bougrine, V. Pasquet and H. Delalu [22] developed the mathematical model of NAminopiperidine (NAPP) synthesis and solved the nonlinear equations using Runge-Kutta methods. To the author's knowledge no analytical expression for concentration in NAPP synthesis and yield has been reported. In this paper, we find a consistent approximate analytical expression of concentrations and yield in the synthesis of NAPP using a new approach to homotopy perturbation method for all values of rate constant and time. The obtained analytical results is used to predict the evolution of the system (yield) as a function of the reagent concentrations ratio and rate constants ratio. The accuracy of the derived expressions for concentration is compared with MATLAB generated numerical simulations and satisfactory agreement is noted. In the next section, the basic concept of the new approach to homotopy perturbation method is described.

\section{BASIC CONCEPT OF NEW APPROACH TO HOMOTOPY PERTURBATION METHOD}

The HPM was proposed first by He [8] for solving differential and integral equations, both linear and nonlinear. In this section, we present a new approach to homotopy perturbation method (NAHPM) as a tool for solving nonlinear ordinary differential equations with initial conditions. HPM provides an approximate solution to a wide range of nonlinear problems, but NAHPM provides the approximate analytical solution with a minimum number of iterations. Consider a general system of nonlinear equation in the form:

$$
\begin{gathered}
A(u(t))=f(u(t), v(t)) \\
A(v(t))=g(u(t), v(t)), t \in \Gamma
\end{gathered}
$$

The boundary conditions are

$$
B\left(u, \frac{\partial u}{\partial n}\right)=0, t \in \Gamma
$$

where A is any differential operator and B is a boundary operator and $\Gamma$ is the boundary of the domain $\Omega$. $\mathrm{f}(\mathrm{u}, \mathrm{v})$ and $\mathrm{g}(\mathrm{u}, \mathrm{v})$ are nonlinear terms. In this method, first we can write $\mathrm{u}(\mathrm{t})$ in Taylor series expression.

$$
u(t)=u(t=0)+t u^{\prime}(t=0)+\frac{t^{2}}{2 !} u^{\prime \prime}(t=0)+\ldots \approx u(t=0)
$$

Using this Taylor series expression, we can bring the nonlinear equation (1) into the linear form. Now we can construct the homotopy $\mathrm{u}: \quad \Omega \times[0,1] \rightarrow \mathrm{R} \quad \& \quad \mathrm{v}: \quad \Omega \times[0,1] \rightarrow \mathrm{R}$ satisfying: $H(u, p)=(1-p)[L(u(t, p))+f(u, v(t=0))]+p[L(u(t, p))+N(u(t, p))-f(u, v)]=0$

$H(v, p)=(1-p)\left[L(v(t, p))+g\left(u_{0}, v\right)\right]+p[L(v(t, p))+N(v(t, p))-g(u, v)]=0$

where $p \in[0,1]$ is an impeding parameter, $t \in \Omega$ and $\mathrm{u}_{0}(\mathrm{t})$ is the initial approximation to the solution of (1) that satisfies the boundary conditions. The NAHPM uses the parameter $\mathrm{p}$ as a small parameter, and assumes that the solutions of (5) can be written as a power series in p:

$$
\begin{aligned}
& u(t, p)=\sum_{j=0}^{\infty} p^{j} u_{j}(t)=u_{0}(t)+p u_{1}(t)+p^{2} u_{2}(t)+\ldots \\
& v(t, p)=\sum_{j=0}^{\infty} p^{j} v_{j}(t)=v_{0}(t)+p v_{1}(t)+p^{2} v_{2}(t)+\ldots
\end{aligned}
$$

where $\mathrm{u}_{0}, \mathrm{u}_{1}, \mathrm{u}_{2}, \ldots$ and $\mathrm{v}_{0}, \mathrm{v}_{1}, \mathrm{v}_{2}, \ldots$ are unknown functions to be determined. Substituting (7) and (8) into (5) and (6) and matching identical powers of $p$ terms, provides the values of the sequence $u_{0}, u_{1}, u_{2}, \ldots$ and $v_{0}, v_{1}$, $\mathrm{v}_{2}, \ldots$ iteratively. Then, as $\mathrm{p} \rightarrow 1$, the solution of (1) and (2) is given by:

$$
\begin{aligned}
& u(t)=\lim _{p \rightarrow 1} u(t, p)=\sum_{j=0}^{\infty} u_{j}(t)=u_{0}(t)+u_{1}(t)+u_{2}(t)+\ldots \\
& v(t)=\lim _{p \rightarrow 1} v(t, p)=\sum_{j=0}^{\infty} v_{j}(t)=v_{0}(t)+v_{1}(t)+v_{2}(t)+\ldots
\end{aligned}
$$

Here we can apply this method to solve the nonlinear problem in NAPP synthesis.

$$
\text { III. MATHEMATICAL FORMULATION OF NAPP SYNTHESIS PROBLEM }
$$

$\mathrm{N}$-aminopiperidine (NAPP) is used for plant protection, in cosmetology and photographic chemistry. Other uses include the manufacturing of paper and transparent recording films, inhibitor composition, and amine- 
based solvent-resistant compounds. The synthesis process of hydroxylamine-O-sulfonique acid (HOSA) has many advantages: it is as pure as the Raschig (water chemistry with no pollutant reagents) process. HOSA is more durable than monochloramine, easier to transport, more condensed solutions can be stored, and the synthesis can be operated batch-wise or continuously in a thinner fashion.

E. Labarthe, A.J. Bougrine, V. Pasquet and H. Delalu [22] developed the kinetic modelling of synthesis of NAPP from HOSA and piperidine (PP) using differential equations. A reaction sequence for the NAPP synthesis with HOSA is described as follows:

$$
\begin{gathered}
\mathrm{NH}_{2} \mathrm{OSO}_{3} \mathrm{H}+\mathrm{OH}^{-} \rightarrow \mathrm{NH}_{2} \mathrm{OSO}_{3}^{-}+\mathrm{H}_{2} \mathrm{O} \\
\mathrm{NH}_{2} \mathrm{OSO}_{3}^{-}+\mathrm{C}_{5} \mathrm{H}_{10} \mathrm{NH} \stackrel{k_{1}}{\longrightarrow} \mathrm{C}_{5} \mathrm{H}_{10} \mathrm{NNH}_{2}+\mathrm{HSO}_{4}^{-} \\
\mathrm{OH}^{-}+\mathrm{HSO}_{4}^{-} \rightarrow \mathrm{SO}_{4}^{2-}+\mathrm{H}_{2} \mathrm{O} \\
\mathrm{C}_{5} \mathrm{H}_{10} \mathrm{NNH}_{2}+\mathrm{NH}_{2} \mathrm{OSO}_{3}^{-} \stackrel{\mathrm{K}_{2}}{\longrightarrow} \mathrm{C}_{5} \mathrm{H}_{10^{N^{+}}=N^{-}+\mathrm{NH}_{4}^{+}}+\mathrm{SO}_{4}^{2-} \\
\mathrm{OH}^{-}+\mathrm{NH}_{4}^{+} \stackrel{\mathrm{K}_{2}}{\longrightarrow} \mathrm{NH}_{3}+\mathrm{H}_{2} \mathrm{O} \\
2 \mathrm{C}_{5} \mathrm{H}_{10^{-}} \mathrm{N}^{+}=\mathrm{N}^{-} \rightarrow \mathrm{C}_{5} \mathrm{H}_{10} \mathrm{NN}^{2} \mathrm{NNC}_{5} \mathrm{H}_{10}
\end{gathered}
$$

NAPP synthesis using hydroxylamine-O-sulfonic acid and piperidine is described by the system of nonlinear differential equations as follows [22]:

$$
\begin{gathered}
\frac{d x(t)}{d t}=-k_{1} x(t) a(t)-k_{2} x(t) u(t) \\
\frac{d a(t)}{d t}=-k_{1} x(t) a(t) \\
\frac{d u(t)}{d t}=k_{1} x(t) a(t)-k_{2} x(t) u(t) \\
\frac{d b(t)}{d t}=-2\left[k_{1} x(t) a(t)+k_{2} x(t) u(t)\right] \\
\frac{d f(t)}{d t}=k_{2} x(t) u(t)
\end{gathered}
$$

The initial conditions are

$$
x(0)=x_{0}^{*}, a(0)=a_{0}^{*}, u(0)=0, b(0)=b_{0}^{*} \text { and } f(0)=0
$$

where $\mathrm{x}, \mathrm{a}, \mathrm{u}, \mathrm{b}$ and $\mathrm{f}$ are the concentrations of hydroxylamine-O-sulfonique acid (HOSA), piperidine (PP), Naminopiperidine (NAPP), sodium hydroxide $(\mathrm{NaOH})$ and diazene $\left(\mathrm{N}_{2} \mathrm{H}_{2}\right)$, at instant $\mathrm{t}$, respectively and $\mathrm{k}_{1}$ and $\mathrm{k}_{2}$ are rate constants. From (11) and (14), it is evident that

$$
\frac{d b(t)}{d t}=2 \frac{d x(t)}{d t}
$$

(17) Integrating on both sides and using the boundary

conditions (16) we get

$$
b(t)=2 x(t)+b_{0}^{*}-2 x_{0}^{*}
$$

From (11), (12) and (15), it is noticeable that

$$
\frac{d f(t)}{d t}=\frac{d a(t)}{d t}-\frac{d x(t)}{d t}
$$

From the above equation we get,

$$
f(t)=a(t)-x(t)+x_{0}^{*}-a_{0}^{*}
$$

Using this relation, the system of five ordinary differential equations (11)-(15) can be reduced to just three:

$$
\begin{gathered}
\frac{d x(t)}{d t}=-k_{1} x(t) a(t)-k_{2} x(t) u(t) \\
\frac{d a(t)}{d t}=-k_{1} x(t) a(t)
\end{gathered}
$$




$$
\frac{d u(t)}{d t}=k_{1} x(t) a(t)-k_{2} x(t) u(t)
$$

with initial conditions

$$
x(0)=x_{0}^{*}, a(0)=a_{0}^{*}, u(0)=0
$$

This is the nonlinear differential equation system that we are going to solve analytically using the new approach to homotopy perturbation method in a simple and closed form. The NAPP yield is defined as [22]:

$$
\varphi_{u}=\frac{u_{s S}}{x_{0}^{*}}
$$

where $\mathrm{u}_{\mathrm{ss}}$ denotes the steady state concentration of NAPP.

IV. CONCENTRATIONS IN NAPP SYNTHESIS USING NEW APPROACH TO HOMOTOPY PERTURBATION METHOD Consider the functions $\mathrm{x}(\mathrm{p}, \mathrm{t}), \mathrm{a}(\mathrm{p}, \mathrm{t})$ and $\mathrm{u}(\mathrm{p}, \mathrm{t})$ of the form:

$$
\begin{aligned}
& x(p, t)=x_{0}(t)+p x_{1}(t)+p^{2} x_{2}(t)+\ldots \\
& a(p, t)=a_{0}(t)+p a_{1}(t)+p^{2} a_{2}(t)+\ldots \\
& u(p, t)=u_{0}(t)+p u_{1}(t)+p^{2} u_{2}(t)+\ldots
\end{aligned}
$$

so that three homotopies can be constructed as:

$$
\begin{gathered}
H(x, p)=(1-p)\left[\frac{d x(t)}{d t}+k_{1} x(t) a(t=0)\right]+p\left[\frac{d x(t)}{d t}+k_{1} x(t) a(t)+k_{2} x(t) u(t)\right]=0 \\
H(a, p)=(1-p)\left[\frac{d a(t)}{d t}+k_{1} x_{0}(t) a(t)\right]+p\left[\frac{d a(t)}{d t}+k_{1} x(t) a(t)\right]=0(30) \\
H(u, p)=(1-p)\left[\frac{d u(t)}{d t}-k_{1} x_{0}(t) a_{0}(t)+k_{2} x_{0}(t) u(t)\right]+p\left[\frac{d u(t)}{d t}-k_{1} x(t) a(t)+k_{2} x(t) u(t)\right]=0
\end{gathered}
$$

By substituting (26)-(28) into (29)-(31), and matching terms of the same power of p, we can compute the functions $\mathrm{x}_{0}, \mathrm{x}_{1}, \mathrm{x}_{2}, \ldots, \mathrm{a}_{0}, \mathrm{a}_{1}, \mathrm{a}_{2}, \ldots$ and $\mathrm{u}_{0}, \mathrm{u}_{1}, \mathrm{u}_{2}, \ldots$.The explicitly solvable sequence of ODEs can be obtained for (29)-(31) as follows:

$$
\begin{gathered}
p^{0}: \frac{d x_{0}(t)}{d t}+k_{1} a_{0}^{*} x_{0}(t)=0 \\
p^{0}: \frac{d a_{0}(t)}{d t}+k_{1} x_{0}(t) a_{0}(t)=0 \\
p^{0}: \frac{d u_{0}(t)}{d t}-k_{1} x_{0}(t) a_{0}(t)+k_{2} x_{0}(t) u_{0}(t)=0 \\
p^{1}: \frac{d x_{1}(t)}{d t}+k_{1} a_{0} x_{1}(t)-k_{1} a_{0} x_{0}+k_{1} x_{0} a_{0}+k_{2} x_{0} u_{0}=0
\end{gathered}
$$

The corresponding initial conditions are

$$
x_{0}(0)=x_{0}^{*}, a_{0}(0)=a_{0}^{*}, u_{0}(0)=0, x_{1}(0)=0
$$

Solving (32)-(35) using the boundary conditions (36), the following results can be obtained.

$$
\begin{gathered}
x_{0}(t)=x_{0}^{*} \exp \left(-k_{1} a_{0}^{*} t\right) \\
a_{0}(t)=a_{0}^{*} \exp \left(\frac{x_{0}^{*}\left(\exp \left(-k_{1} a_{0}{ }^{*}\right)-1\right)}{a_{0}^{*}}\right)
\end{gathered}
$$




$$
\begin{aligned}
u_{0}(t)= & \frac{k_{1} a_{0}^{*}}{k_{1}-k_{2}}\left[\exp \left(k_{2} x_{0}^{*} \frac{\exp \left(-k_{1} a_{0}^{*} t\right)}{k_{1} a_{0}^{*}}\right)\right] \\
& {\left[\exp \left(-\frac{k_{2} x_{0}^{*}}{k_{1} a_{0}^{*}}\right)-\exp \left(x_{0}^{*} \frac{\left(k_{1}-k_{2}\right) \exp \left(-k_{1} a_{0} t\right)-k_{1}}{k_{1} a_{0}^{*}}\right)\right] }
\end{aligned}
$$

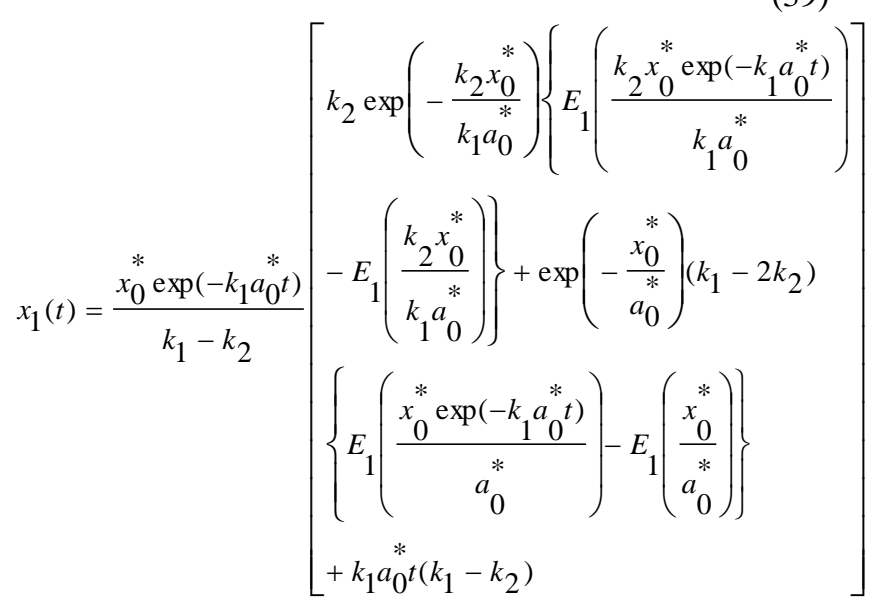

$$
\begin{aligned}
& a_{1}(t)=\left[\frac { k _ { 1 } x _ { 0 } ^ { * } a _ { 0 } ^ { * } } { k _ { 1 } - k _ { 2 } } \operatorname { e x p } ( \frac { x _ { 0 } ^ { * } } { a _ { 0 } ^ { * } } \operatorname { e x p } ( - k _ { 1 } a ^ { * } t ) ] \left[\begin{array} { l } 
{ t } \\
{ \int _ { 0 } } \\
{ 0 }
\end{array} k _ { 2 } \left\{E_{1}\left(\frac{k_{2} x_{0}^{*}}{k_{1} a_{0}^{*}}\right)\right.\right.\right. \\
& \left.-E_{1}\left(\frac{k_{2} x_{0}^{*} \exp \left(-k_{1} a_{0}^{*} z\right)}{k_{1} a_{0}^{*}}\right)\right\} \exp \left(\frac{-k_{1}^{2} a_{0}^{* 2} z-k_{1} x_{0}^{*}-k_{2} x_{0}^{*}}{k_{1} a_{0}^{*}}\right) \\
& +\left(k_{1}-2 k_{2}\right)\left\{E_{1}\left(\frac{x_{0}^{*}}{a_{0}^{*}}\right)-E_{1}\left(\frac{x_{0}^{*} \exp \left(-k_{1} a_{0} z\right)}{a_{0}^{*}}\right)\right\} \\
& \left.\left.\exp \left(\frac{-k_{1}^{2} a_{0}^{2} z-2 x_{0}^{*}}{a_{0}^{*}}\right)-\exp \left(\frac{-k_{1}^{2} a_{0}^{*} z-x_{0}}{a_{0}^{*}}\right) k_{1}^{*} a_{0}^{*}\left(k_{1}-k_{2}\right) z\right] d z\right]
\end{aligned}
$$

where $\mathrm{E}_{1}$ represents exponential integral, $E_{1}(x)=\int_{-\infty}^{x} \frac{e^{t}}{t} d t$. The approximate solution of (21) - (23), when $\mathrm{p} \rightarrow 1$, will be as follows:

$$
\begin{aligned}
x(t) & \approx x_{0}(t)+x_{1}(t) \\
a(t) & \approx a_{0}(t)+a_{1}(t) \\
u(t) & \approx u_{0}(t)
\end{aligned}
$$
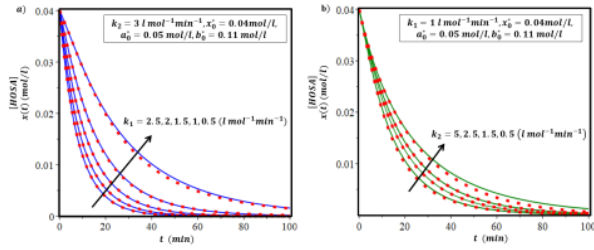

The approximate analytical expressions of $b(t)$ and $f(t)$ can be obtained easily by using $x(t)$ and $a(t)$ in $(18)$ and (20)

$$
\text { V. ANALYTICAL EXPRESSION OF STEADY STATE CONCENTRATIONS }
$$

When $\mathrm{t}=\infty$, the concentration of HOSA, PP, NAPP, $\mathrm{NaOH}$ and diazene $\mathrm{N}_{2} \mathrm{H}_{2}$ are

$$
x_{s s}=0
$$




$$
\begin{gathered}
a_{s s}=a_{0}^{*} \exp \left(-\frac{x_{0}^{*}}{a_{0}^{*}}\right) \\
u_{S S}=\frac{k_{1} a_{0}^{*}}{k_{1}-k_{2}}\left[\exp \left(-\frac{k_{2} x_{0}^{*}}{k_{1} a_{0}^{*}}\right)-\exp \left(-\frac{x_{0}^{*}}{a_{0}^{*}}\right)\right] \\
b_{s s}=b_{0}^{*}-2 x_{0}^{*} \\
f_{S S}=a_{0}^{*} \exp \left(-\frac{x_{0}^{*}}{a_{0}^{*}}\right)+x_{0}^{*}-a_{0}^{*}
\end{gathered}
$$

The analytical expression of NAPP yield using (25) is

$$
\varphi_{u}(p, r)=\frac{u_{s S}}{x_{0}^{*}}=\frac{p}{(1-r)}\left[\exp \left(-\frac{r}{p}\right)-\exp \left(-\frac{1}{p}\right)\right] \quad \text { (50) where } p=\frac{a_{0}^{*}}{x_{0}^{*}} \text { and } r=\frac{k_{2}}{k_{1}} \text {. Here yield } \varphi_{u} \text {, depends }
$$

only on reagents ratio $\mathrm{p}$ and rate constants ratio $\mathrm{r}$ which is a function of $\mathrm{pH}$ and temperature.

\section{NUMERICAL SIMULATION}

The system of nonlinear rate equations was solved numerically to examine the accuracy of the solution obtained using a new approach to homotopy perturbation method. The numerical solution can be obtained using the MATLAB software program. In Figs. (1)-(5), analytical results of concentration of HOSA, PP, NAPP, NaOH and diazene are compared with the corresponding numerical results graphically for different values of the parameter. The comparison verified that the numerical results match very well with our analytical results obtained. The average deviation between the analytical and numerical results using the NAHPM is less than $1 \%$ (Refer to Table 1).

\section{RESULT AND DISCUSSION}

Equations (42)-(44) represent the approximate analytical expressions of concentration of HOSA, PP, NAPP. The obtained analytical results are compared with numerical solution, which is provided in Figs. (1)-(6). From the figures it is observed that the concentration of NAPP and $\mathrm{N}_{2} \mathrm{H}_{2}$ is an increasing function, while that of HOSA, $\mathrm{PP}$ and $\mathrm{NaOH}$ are decreasing functions with respect to time.

Fig. 1. Concentration of HOSA $(x(t))$ against time $t$ for various values of rate constants. Solid line represents numerical result and dotted line represents analytical result (42).

The concentrations of HOSA profiles are shown in Figs. 1(a) and 1(b) for different values of rate constant. From Fig. 1 it is observed that the concentration of HOSA increases as the rate constants $\mathrm{k}_{1}$ and $\mathrm{k}_{2}$ decreases. Also it is noted that at $\mathrm{t}=100 \mathrm{~min}$, the concentration of HOSA reaches its steady-state value.
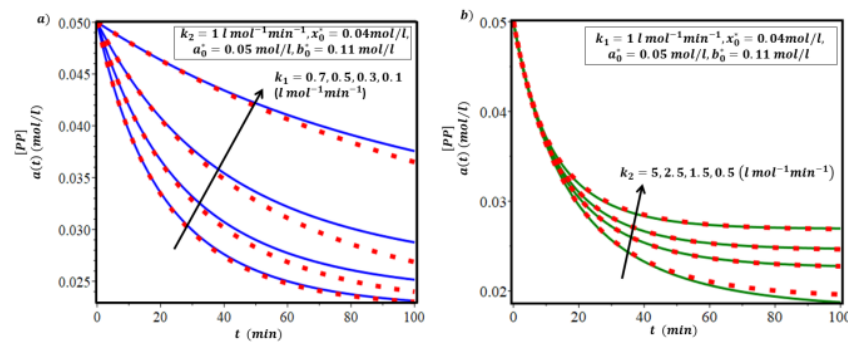

Fig. 2. Concentration of piperidine $(\mathrm{a}(\mathrm{t}))$ against time $t$ for various values of rate constants. Solid line represents numerical result and dotted line represents analytical result (43).

Fig. 2 represents the concentration of piperidine versus time $t$ for various values of rate constant $\mathrm{k}_{1}$ and $\mathrm{k}_{2}$. From Fig. 2, it is inferred that the concentration of piperidine increases when the rate constant $\mathrm{k}_{1}$ and $\mathrm{k}_{2}$ decreases for some fixed values of $\mathrm{x}_{0}{ }^{*}$ and $\mathrm{a}_{0}{ }^{*}$. As time increases it is observed that $\mathrm{a}(\mathrm{t})$ approaches $\mathrm{a}_{0}{ }^{*} \exp (-$ $\mathrm{x}_{0} * / \mathrm{a}_{0} *$ ) and after that it becomes steady.
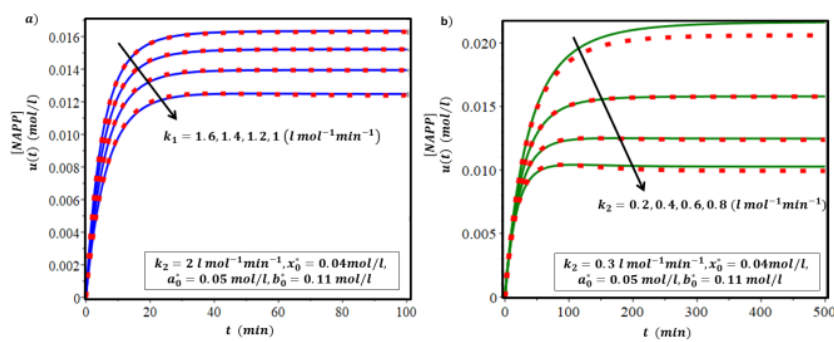

Fig. 3. Concentration of NAPP $(u(t))$ against time $t$ for various values of rate constants. Solid line represents numerical result and dotted line represents analytical result (44).

The effects of rate constant on concentration profiles of NAPP are shown in Figs. 3(a) and 3(b). From Fig. 3(a), it is investigated that the 
concentration of NAPP increases when $\mathrm{k}_{1}$ increases for some fixed values of $\mathrm{x}_{0}{ }^{*}$ and $\mathrm{a}_{0}{ }^{*}$. The concentration of NAPP reaches the steady-state value when $\mathrm{t}=20 \mathrm{~min}$ for different values of $\mathrm{k}_{1}$. From Fig. $3(\mathrm{~b})$, it is noticed that $\mathrm{u}(\mathrm{t})$ and $\mathrm{k}_{2}$ are inversely related. When $\mathrm{t}=150 \mathrm{~min}$ for varying values of $\mathrm{k}_{2}$, the NAPP concentration approaches steady-state value.
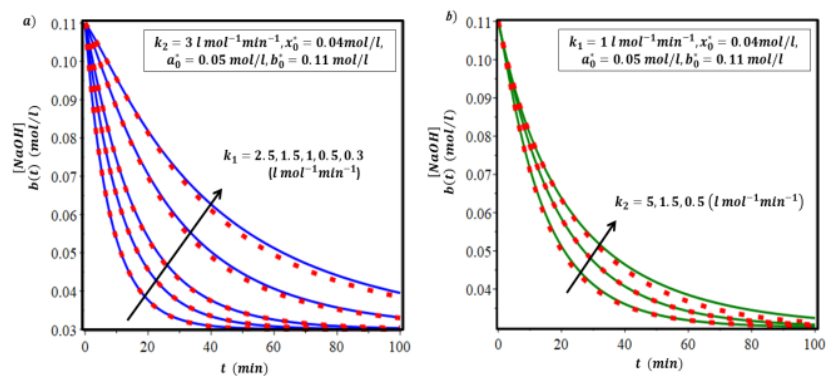

to be $\mathrm{b}_{0} *-2 \mathrm{x}_{0} *$.
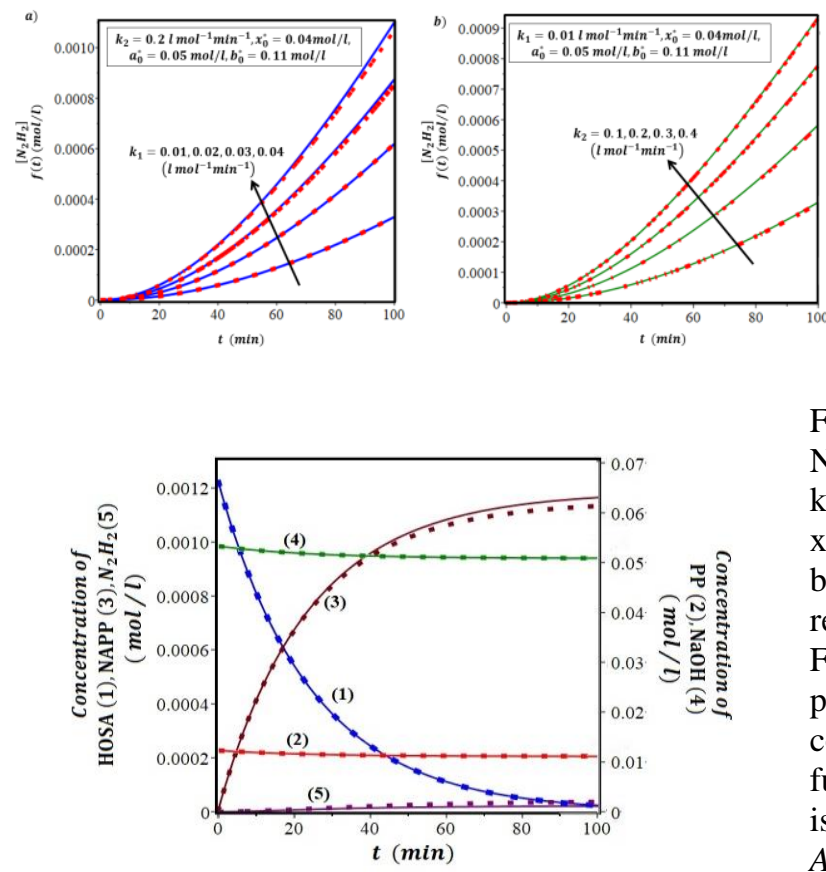

Fig. 7 (a). Comparison of analytical result (50) of yield with experimental result [22] at $\mathrm{k}_{1}=3.391 \mathrm{~mol}^{-1} \mathrm{~min}^{-1}$ and $\mathrm{k}_{1}=1.17 \mathrm{~mol}^{-1} \mathrm{~min}^{-1}$ (b). Effect of ratio of rate constants $r$ and reagents ratio $p$ on yield (50) (c). Profile of yield $\varphi_{u}$ over reagent ratio $p$ and ratio of rate constants $r$.

The comparison of analytical results of NAPP yield with experimental results for fixed values of $k_{1}$ and $k_{2}$ is shown in Fig. 7(a) The satisfactory agreement is noted. From Fig. 7(b) it is observed that yield decreases for a higher ratio of rate constants $\mathrm{r}$. The NAPP yield reaches $90 \%$ at $\mathrm{p}=8$. For $\mathrm{p}>8$, there is a negligible increase in the yield. It is noted that the NAPP yield increases for higher reagents ratio $\mathrm{p}$. It can be found from Fig. 7(c) that when the rate constant ratio $r$ is very small and the reagent ratio $\mathrm{p}$ exceeds 15 , the peak value of yield is obtained.
Fig. 4. Concentration of $\mathrm{NaOH}(\mathrm{b}(\mathrm{t}))$ against time $\mathrm{t}$ for various values of rate constants. Solid line represents numerical result and dotted line represents analytical result (18).

The concentration profiles of $\mathrm{NaOH}$ versus time $t$ for different values of reaction parameter $\mathrm{k}_{1}$ and $\mathrm{k}_{2}$ are displayed in the Figs. 4(a) and 4(b). It can be inferred from the figures that decrease in rate constants leads to increase in concentration of $\mathrm{NaOH}$ for some fixed values of other parameters. This concentration stabilizes for larger value of $t$ and it is observed

Fig. 5. Concentration of diazene $(f(t))$ against time $\mathrm{t}$ for various values of rate constants. Solid line represents numerical result and dotted line represents analytical result (20).

The influence of rate constant on concentration profiles of diazene are shown in Figs. 5(a) and 5(b). From these figures, it is noted that the concentration of diazene increases when $\mathrm{k}_{1}, \mathrm{k}_{2}$ increases. As time approaches larger value, $f(t)$ approaches a constant value which is given in (49).

Fig. 6. Plot of concentration of HOSA (1), PP (2), NAPP (3), $\mathrm{NaOH}$ (4) and $\mathrm{N}_{2} \mathrm{H}_{2}$ (5) against time t for $\mathrm{k}_{1}=3.391 \mathrm{~mol}^{-1} \mathrm{~min}^{-1}, \quad \mathrm{k}_{2}=1.171 \mathrm{~mol}^{-1} \mathrm{~min}^{-1}$, $\mathrm{x}_{0}{ }^{*}=1.23 \times 10^{-3} \mathrm{~mol} / \mathrm{l}, \quad \mathrm{a}_{0}{ }^{*}=1.23 \times 10^{-2} \quad \mathrm{~mol} / \mathrm{l}$, $\mathrm{b}_{0}{ }^{*}=5.33 \times 10^{-2} \mathrm{~mol} / \mathrm{l}$. Solid line represents numerical result and dotted line represents analytical result Fig. 6 illustrates the behaviour of all concentration profiles. From this figure, it is observed that the concentration of HOSA $(x(t))$ is a strictly decreasing function, whereas the concentration of NAPP $(u(t))$ is a strictly increasing function.

A. Influence of reagent ratio $p \&$ ratio of rate constants $r$ on yield

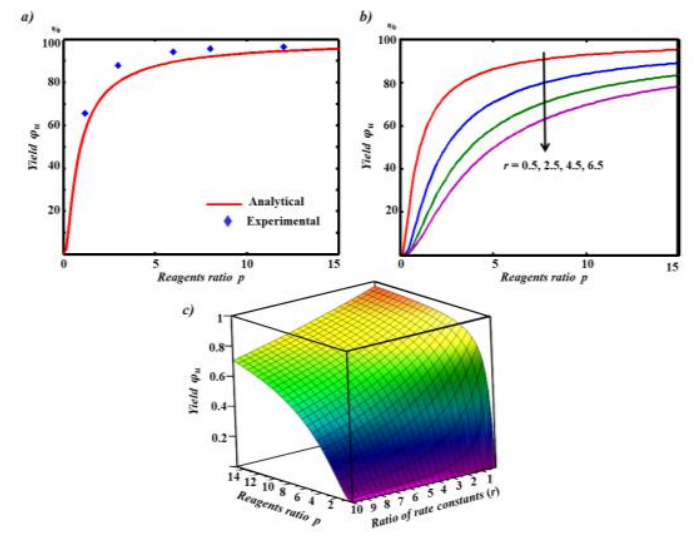


B. Differential sensitive analysis of parameters: ratio of rate constants $r$ and reagents ratio $p$

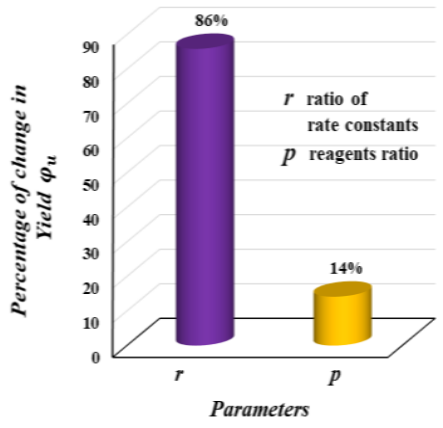

Fig. 8. Sensitivity analysis of parameters, ratio of rate constants $r$ and reagents ratio $p$ : Percentage change in yield $\varphi_{\mathrm{u}}$.

Equation (50) represents the new approximate analytical expression for NAPP yield in terms of the parameters such as the ratio of rate constants $r$ and reagents ratio $p$. By differentiating the NAPP yield partially for these parameters, the impact of the parameters over NAPP yield can be determined [23, 24]. The percentage of change in NAPP yield for $r$ and $p$ are $86 \%$ and $14 \%$. From this, it is evident that the ratio of rate constants $r$ has more impact on NAPP yield when it is varied. In contrast, the remaining parameter, reagents ratio p accounts for only small changes in yield. The analysis of these results is described in Fig. 8 and confirmed in the Figs. 7(a) $7(\mathrm{c})$.

\section{CONCLUSION}

The new analytic approach of the homotopy perturbation method is being used because of the difficulties in solving the nonlinear differential equations in NAPP synthesis. In this paper, the time-dependent nonlinear rate equation was solved analytically. The obtained results have a good agreement with those numerical and experimental results. This work's primary result is a simple approximate calculation of concentration and yield for all possible parameters such as the ratio of rate constants $r$ and reagents ratio $\mathrm{p}$. It is beneficial and simple, and only a few iterations are needed to find an approximate solution. The analytical results are useful to characterize the reaction mechanism and predict the behaviour of NAPP synthesis.

TABLE I. COMPARISON BETWEEN NUMERICAL AND ANALYTICAL (NAHPM) RESULTS OF CONCENTRATIONS OF HOSA, PP AND NAPP FOR VARIOUS VALUES OF PARAMETERS.

\begin{tabular}{|c|c|c|c|c|c|c|c|c|c|}
\hline \multirow{2}{*}{$\begin{array}{c}t \\
(\mathrm{~min})\end{array}$} & \multicolumn{3}{|c|}{$\begin{array}{c}\text { Concentration of HOSA } \\
\mathrm{k}_{1}=1 \mathrm{lmol}^{-1} \mathrm{~min}^{-1}, \mathrm{k}_{2}=2.5 \mathrm{lmol}^{-1} \mathrm{~min}^{-1} \\
\mathbf{x}_{0}{ }^{*}=0.04 \mathrm{~mol}^{\prime} / \mathrm{l}, \mathrm{a}_{0}{ }^{*}=0.05 \mathrm{~mol}^{\prime} / \mathrm{l}, \\
\mathrm{b}_{0}{ }^{*}=0.11 \mathrm{~mol} / \mathrm{l}\end{array}$} & \multicolumn{3}{|c|}{$\begin{array}{c}\text { Concentration of PP } \\
\mathrm{k}_{1}=0.7 \mathrm{lmol}^{-1} \mathrm{~min}^{-1}, \mathrm{k}_{2}=1 \mathrm{lmol}^{-1} \mathrm{~min}^{-1} \\
\mathbf{x}_{0}{ }^{*}=0.04 \mathrm{~mol}^{\prime} / \mathrm{l}, \mathbf{a}_{0}{ }^{*}=0.05 \mathrm{~mol} / \mathrm{l} \\
\mathrm{b}_{0}{ }^{*}=0.11 \mathrm{~mol} / \mathrm{l}\end{array}$} & \multicolumn{3}{|c|}{$\begin{array}{c}\text { Concentration of NAPP } \\
\mathrm{k}_{1}=1.6 \mathrm{lmol}^{-1} \mathrm{~min}^{-1}, \mathrm{k}_{2}=2 \mathrm{lmol}^{-1} \mathrm{~min}^{-1} \\
\mathrm{x}_{0}{ }^{*}=0.04 \mathrm{~mol}^{\prime} / \mathrm{a}_{0}{ }^{*}=0.05 \mathrm{~mol} / \mathrm{l} \\
\mathrm{b}_{0}{ }^{*}=0.11 \mathrm{~mol} / \mathrm{l}\end{array}$} \\
\hline & $\begin{array}{c}\text { Numeric } \\
\text { al }\end{array}$ & $\begin{array}{c}\text { Analytical } \\
(42)\end{array}$ & $\begin{array}{c}\% \text { of } \\
\text { deviation }\end{array}$ & Numerical & $\begin{array}{c}\text { Analytical } \\
(43)\end{array}$ & $\begin{array}{c}\text { \%of } \\
\text { deviati } \\
\text { on }\end{array}$ & $\begin{array}{c}\text { Numeric } \\
\text { al }\end{array}$ & $\begin{array}{c}\text { Analytical } \\
(44)\end{array}$ & $\begin{array}{c}\% \text { of } \\
\text { deviation }\end{array}$ \\
\hline 0 & 0.0400 & 0.0400 & 0.00 & 0.0500 & 0.0500 & 0.00 & 0.0000 & 0.0000 & 0.00 \\
\hline 10 & 0.0226 & 0.0225 & 0.44 & 0.0396 & 0.0395 & 0.25 & 0.0135 & 0.0134 & 0.74 \\
\hline 20 & 0.0127 & 0.0125 & 1.57 & 0.0336 & 0.0334 & 0.60 & 0.0157 & 0.0156 & 0.64 \\
\hline 30 & 0.0072 & 0.0071 & 1.39 & 0.0299 & 0.0297 & 0.67 & 0.0161 & 0.0161 & 0.00 \\
\hline 40 & 0.0041 & 0.0041 & 0.00 & 0.0276 & 0.0274 & 0.72 & 0.0163 & 0.0162 & 0.61 \\
\hline 50 & 0.0024 & 0.0024 & 0.00 & 0.0261 & 0.0258 & 1.15 & 0.0163 & 0.0163 & 0.00 \\
\hline 60 & 0.0014 & 0.0014 & 0.00 & 0.0251 & 0.0248 & 1.20 & 0.0163 & 0.0163 & 0.00 \\
\hline 70 & 0.0008 & 0.0008 & 0.00 & 0.0243 & 0.0241 & 0.82 & 0.0163 & 0.0163 & 0.00 \\
\hline 80 & 0.0005 & 0.0005 & 0.00 & 0.0238 & 0.0236 & 0.84 & 0.0163 & 0.0163 & 0.00 \\
\hline 90 & 0.0003 & 0.0003 & 0.00 & 0.0233 & 0.0232 & 0.43 & 0.0163 & 0.0163 & 0.00 \\
\hline 100 & 0.0002 & 0.0002 & 0.00 & 0.0229 & 0.0230 & 0.44 & 0.0163 & 0.0163 & 0.00 \\
\hline
\end{tabular}

TABLE II.

FORMATION OF NAPP FOR. 


\begin{tabular}{|c|c|c|c|c|c|c|}
\hline \multirow{2}{*}{$\mathbf{p}=\mathbf{a}_{0}{ }^{*} / \mathbf{x}_{0}{ }^{*}$} & \multicolumn{4}{|c|}{ Real concentration in the reaction medium, $\mathrm{mol} / \mathrm{I}$} & \multirow{3}{*}{$\begin{array}{c}\text { Yield }=\mathbf{u}_{\text {ss }} / \\
\mathbf{x}_{0}^{*} \% \\
\text { Labarthe et } \\
\text { al. }[22] \\
\text { (Experimental } \\
\text { ) }\end{array}$} & \multirow[b]{3}{*}{$\begin{array}{c}\text { Yield }=\mathbf{u}_{\text {ss }} / \mathbf{x}_{0}{ }^{*} \% \\
(\mathbf{5 0})\end{array}$} \\
\hline & \multicolumn{2}{|c|}{$t=0$} & \multicolumn{2}{|c|}{$\mathbf{t}=\infty$} & & \\
\hline $\mathbf{p}=\mathbf{a}_{0}{ }^{*} / \mathbf{x}_{0}{ }^{*}$ & $\begin{array}{c}{[\mathrm{HOSA}]_{0},} \\
\left(\mathrm{x}_{0}{ }^{*}\right) \\
\text { Labarthe et } \\
\text { al. }[22] \& \text { this } \\
\text { work }\end{array}$ & $\begin{array}{c}{[P P]_{0},\left(\mathrm{x}_{0}{ }^{*}\right)} \\
\text { Labarthe et } \\
\text { al. }[22] \& \text { this } \\
\text { work }\end{array}$ & $\begin{array}{l}{[\mathrm{NAPP}]_{\infty},} \\
\left(\mathrm{u}_{\mathrm{ss}}\right) \\
\text { Labarthe et } \\
\quad \text { al. [22] }\end{array}$ & $\begin{array}{c}{[\mathbf{N A P P}]_{\infty},} \\
\left(\mathbf{u}_{\mathrm{ss}}\right) \\
\text { This work } \\
\quad(\mathbf{4 7})\end{array}$ & & \\
\hline 1.25 & 0.04 & 0.05 & 0.03 & 0.0236 & 65.9 & 59.06 \\
\hline 1.23 & 0.13 & 0.16 & 0.09 & 0.0762 & 66.0 & 58.58 \\
\hline 1.19 & 0.21 & 0.25 & 0.13 & 0.1209 & 64.5 & 57.56 \\
\hline 3 & 0.08 & 0.24 & 0.07 & 0.0641 & 85.9 & 80.08 \\
\hline 6 & 0.04 & 0.24 & 0.04 & 0.0358 & 91.8 & 89.44 \\
\hline 8 & 0.03 & 0.24 & 0.03 & 0.0276 & 93.9 & 91.96 \\
\hline 12 & 0.02 & 0.24 & 0.02 & 0.0189 & 94.6 & 94.56 \\
\hline
\end{tabular}

TABLE III. ANALYTICAL RESULTS OF NAPP YIELD $\Phi_{U}$ FOR VARIOUS RATIO OF RATE CONSTANTS R AND REAGENTS RATION P.

\begin{tabular}{|c|c|c|c|c|c|c|c|}
\hline \multirow{2}{*}{$\mathbf{p}=\mathbf{a}_{\mathbf{0}}{ }^{*} / \mathbf{x}_{\mathbf{0}}{ }^{*}$} & \multirow{2}{*}[\mathbf{pp}]{$_{\mathbf{0}},\left(\mathbf{a}^{*}{ }^{*}\right)$} & \multirow{2}{*}[\mathbf{HOSA}]{$_{\mathbf{0}},\left(\mathbf{x}^{*}{ }^{*}\right)$} & \multicolumn{6}{|c|}{ Yield= $\mathbf{u}_{\mathbf{s s}} / \mathbf{x}^{*}{ }^{*}(\mathbf{5 0})$} \\
\hline 1.25 & 0.05 & 0.04 & 0.658 & 0.5525 & 0.3093 & 0.1347 & $\mathbf{r}=10$ \\
\hline 1.23 & 0.16 & 0.13 & 0.6538 & 0.5472 & 0.3036 & 0.1311 & 0.0606 \\
\hline 1.19 & 0.25 & 0.21 & 0.645 & 0.5364 & 0.2919 & 0.1239 & 0.057 \\
\hline 3 & 0.24 & 0.08 & 0.8356 & 0.7797 & 0.6093 & 0.3957 & 0.227 \\
\hline 6 & 0.24 & 0.04 & 0.9133 & 0.8828 & 0.7797 & 0.6178 & 0.4384 \\
\hline 8 & 0.24 & 0.03 & 0.9341 & 0.9107 & 0.8296 & 0.6945 & 0.5298 \\
\hline
\end{tabular}

\section{Acknowledgment}

The authors are thankful to Shri J. Ramachandran, Chancellor, Col. Dr. G.Thiruvasagam, Vice-Chancellor, Academy of Maritime Education and Training (AMET), Deemed to be University, Chennai, Tamil Nadu for their continuous support.

TABLE IV. NOMENCLATURE

\begin{tabular}{|c|l|c|}
\hline $\begin{array}{c}\text { Symb } \\
\boldsymbol{o l}\end{array}$ & \multicolumn{1}{|c|}{ Description } & Unit \\
\hline$x$ & $\begin{array}{l}\text { Concentration of hydroxylamine-O- } \\
\text { sulfonique acid }\end{array}$ & $\mathrm{mol} / 1$ \\
\hline$a$ & Concentration of piperidine & $\mathrm{mol} / 1$ \\
\hline$u$ & Concentration of N-aminopiperidine & $\mathrm{mol} / 1$ \\
\hline$b$ & Concentration of sodium hydroxide & $\mathrm{mol} / 1$ \\
\hline$f$ & Concentration of diazene & $\mathrm{mol} / 1$ \\
\hline$x_{0}^{*}$ & $\begin{array}{l}\text { Initial concentration of hydroxylamine-O- } \\
\text { sulfonique acid }\end{array}$ & $\mathrm{mol} / 1$ \\
\hline$a_{0}^{*}$ & Initial concentration of piperidine & $\mathrm{mol} / 1$ \\
\hline$b_{0}^{*}$ & Initial concentration of sodium hydroxide & $\mathrm{mol} / 1$ \\
\hline$x_{s S}$ & $\begin{array}{l}\text { Steady state concentration of } \\
\text { hydroxylamine-O-sulfonique acid }\end{array}$ & $\mathrm{mol} / 1$ \\
\hline$a_{s S}$ & Steady state concentration of piperidine & $\mathrm{mol} / 1$ \\
\hline$u_{S S}$ & $\begin{array}{l}\text { Steady state concentration of } \mathrm{N}- \\
\text { aminopiperidine }\end{array}$ & $\mathrm{mol} / 1$ \\
\hline$b_{S S}$ & $\begin{array}{l}\text { Steady state concentration of sodium } \\
\text { hydroxide }\end{array}$ & $\mathrm{mol} / 1$ \\
\hline$f_{S S}$ & Steady state concentration of diazene & $\mathrm{mol} / 1$ \\
\hline
\end{tabular}




\begin{tabular}{|c|l|c|}
\hline $\begin{array}{c}\text { Symb } \\
\boldsymbol{o l}\end{array}$ & \multicolumn{1}{|c|}{ Description } & Unit \\
\hline$k_{1,} k_{2}$ & Rate constants & $\begin{array}{c}\mathrm{lmol}^{-1} \\
\mathrm{~min}^{-1}\end{array}$ \\
\hline $\mathrm{t}$ & Time & $\mathrm{min}$ \\
\hline$p$ & Reagents ratio & none \\
\hline$r$ & Ratio of rate constants & none \\
\hline
\end{tabular}

\section{References}

1. L. Rajendran, R. Swaminathan and M. Chitra Devi, A Closer Look of Nonlinear Reaction-Diffusion Equations. Nova Science Publishers, Inc 2020.

2. L. Rajendran, M. Chitra Devi, C. Fernandez and Q. Peng, Mathematical modeling and simulation of nonlinear process in enzyme kinetics in Advanced Chemical Kinetics. Intech Open Limited, London, 2018.

3. K. Saranya, V. Mohan and L. Rajendran, "Steady-state concentrations of carbon dioxide absorbed into phenyl glycidyl ether solutions by residual method," J. Math. Chem., vol. 58, pp. 1230-1246, 2020.

4. G. Rahamathunissa and L. Rajendran, "Application of He's variational iteration method in nonlinear boundary value problems in enzyme- substrate reaction diffusion processes: part 1. The steady-state amperometric response," J. Math. Chem., vol. 44(3), pp. 849-861 2008.

5. J. Biazar, E. Babolian and R. Islam, "Solution of the system of ordinary differential ,equations by Adomian decomposition method," Appl. Math. Comput., vol. 147(3), pp. 713-719, 2004.

6. L. Bayón, P. Fortuny Ayuso, J.M. Grau, M.M. Ruiz and P.M. Suárez, "Irreversible linear pathways in enzymatic reactions: analytical solution using the homotopy perturbation method", J. Math. Chem., vol. 58, pp. 273-291, 2020.

7. D.D. Ganji and M. Rafei, "Solitary wave solutions for a generalized Hirota-Satsuma coupled KdV equation by homotopy perturbation method," Phys. Lett. A., vol. 356(2), pp. 131-137, 2006.

8. J.H. He, "Homotopy perturbation technique," Comput. Methods. Appl. Mech. Eng., vol.178, pp. $257-$ 262, 1999.

9. D.D. Ganji, A.R. Sahouli and M. Famouri, "A new modification of He's homotopy perturbation method for rapid convergence of nonlinear undamped oscillators," J. Appl. Math. Comput., vol. 30, pp. 181-192, 2009.

10. J.H. He and Y.O. El- Dib, "Homotopy perturbation method for Fangzhu oscillator," J. Math. Chem., vol. 58(10), pp. 2245-2253 (2020).

11. N. Anjum and J.H. He, "Nonlinear dynamic analysis of vibratory behavior of a graphene nano/microelectromechanical system," Math Meth Appl Sci., pp. 1-16, 2020.

12. Y. Wu and J.H. He, "Homotopy perturbation method for nonlinear oscillators with coordinate dependent mass," Results Phys., vol. 10, pp. 270-271, 2018.

13. S. Abbasbandy, "Application of he's homotopy perturbation method for Laplace transform," Chaos. Soliton. Fract., vol. 30, pp. 1206-1212, 2006.

14. D.D. Ganji and A. Sadighi, "Application of he's homotopy-perturbation method to nonlinear coupled systems of reaction-diffusion equations," Int. J. Nonlinear Sci. Numer. Simul., vol. 7(4), pp. 411-418, 2006.

15. M. Rafei, D.D. Ganji and H. Daniali, "Solution of the epidemic model by homotopy perturbation method," Appl. Math. Comput., vol. 187(2), pp. 1056-1062, 2007.

16. Yildirim and T.O Zis, "Solutions of singular ivps of Lane-Emden type by homotopy perturbation method," Phys. Lett. A, vol. 369, pp. 70-76, 2007.

17. Yildirim, "Exact solutions of nonlinear differential-difference equations by He's homotopy perturbation method," Int. J. Nonlinear Sci. Numer. Simul., vol. 9(2), pp. 111-114, 2008.

18. R. Singh, S. Singh and A.M. Wazwaz, "A modified homotopy perturbation method for singular time dependent Emden-Fowler equations with boundary conditions," J. Math. Chem, vol. 54(4), pp. 918 931, 2016.

19. R. Swaminathan, K. Lakshmi Narayanan, V. Mohan, K. Saranya and L. Rajendran, "Reaction/diffusion equation with Michaelis-Menten kinetics in microdisk biosensor: homotopy perturbation method approach," J. Electrochem. Sci., vol. 14, pp. 3777-3791, 2019.

20. K. Saranya, V. Mohan, R. Kizek, C. Fernandez and L. Rajendran, "Unprecedented homotopy perturbation method for solving nonlinear equations in the enzymatic reaction of glucose in a spherical matrix,” Bioproc. Biosyst. Eng., vol. 41(2), pp. 281-294, 2017. 
21. P.G. Jansi Rani, M. Kirthiga, A. Molina, E. Laborda and L. Rajendran, "Analytical solution of the convection-diffusion equation for uniformly accessible rotating disk electrodes via the homotopy perturbation method," J. Electroanal. Chem., vol. 799, pp. 175-180, 2017.

22. E. Labarthe, A.J. Bougrine, V. Pasquet and H. Delalu, Kinetic modelling of synthesis of NAminopiperidine from HydroxylamineOSulfonique acid and Piperidine. Kinet. Catal., vol. 53(1), pp. 25-35, 2012.

23. M. Rasi, L. Rajendran and M.V. Sangaranarayanan, "Enzyme-catalyzed oxygen reduction reaction in biofuel cells: analytical expressions for chronoamperometric current densities," J. Electrochem. Soc., vol. 162(9), pp. H671-H680, 2015.

24. K. Saranya, V. Mohan and L. Rajendran, "Analytical solution of the non-linear equation in biodegradation of N-butanol in a biofilter," Am. J. Analyt. Chem., vol. 11, pp. 172-186, 2020. 